\title{
Improving magnetic properties of ultrasmall magnetic nanoparticles by biocompatible coatings
}

\author{
R. Costo, ${ }^{\text {a) }}$ M. P. Morales, and S. Veintemillas-Verdaguer \\ Departamento de Biomateriales y Materiales Bioinspirados, Instituto de Ciencia de Materiales \\ de Madrid/CSIC, Campus de Cantoblanco, Sor Juana Inés de la Cruz 3, Madrid 28049, Spain
}

(Received 20 June 2014; accepted 3 February 2015; published online 11 February 2015)

\begin{abstract}
This paper deals with the effect of a biocompatible surface coating layer on the magnetic properties of ultrasmall iron oxide nanoparticles. Particles were synthesized by laser pyrolysis and fully oxidized to maghemite by acid treatment. The surface of the magnetic nanoparticles was systematically coated with either phosphonate (phosphonoacetic acid or pamidronic acid) or carboxylate-based (carboxymethyl dextran) molecules and the binding to the nanoparticle surface was analyzed. Magnetic properties at low temperature show a decrease in coercivity and an increase in magnetization after the coating process. Hysteresis loop displacement after field cooling is significantly reduced by the coating, in particular, for particles coated with pamidronic acid, which show a 10\% reduction of the displacement of the loop. We conclude that the chemical coordination of carboxylates and phosphonates reduces the surface disorder and enhances the magnetic properties of ultrasmall maghemite nanoparticles. (C) 2015 AIP Publishing LLC.
\end{abstract}

[http://dx.doi.org/10.1063/1.4908132]

\section{INTRODUCTION}

In a colloidal dispersion the particles always show Brownian motion and hence collide with each other continuously. The stability of these systems is thus determined by the interaction between the particles during such a collision. In the case of magnetic colloids there are always attractive forces between the nanoparticles (van der Waals forces and dipole-dipole interaction) which need to be balanced with repulsive forces to impart stability to the system. This repulsion can be obtained either with an electrical double layer (electrostatic stabilization) or with adsorbed or chemically attached polymeric molecules (steric stabilization). The combination of both stabilization mechanisms leads to electrosteric stabilization.

When biological applications are aimed, the stability of magnetic nanoparticles in aqueous dispersions at physiological $\mathrm{pH}$ and ionic strength becomes a key point. Numerous approaches to this problem are reported in the literature. ${ }^{1}$ Thus, coatings with polysaccharides like dextran ${ }^{2,3}$ polymers ${ }^{4,5}$ or organic molecules and surfactants ${ }^{6,7}$ are becoming very popular due to the low effect on its stability of the buffers employed in biochemistry. Inorganic coatings as those based on silica, ${ }^{8,9}$ gold, ${ }^{10-12}$ and carbon ${ }^{13,14}$ seem to be very promising as well due to their resistance to degradation and functionalization possibilities. Many recent studies have focused on multilayer coatings which are used to tune the nanoparticles surface and add extra-functionality. For instance, charged molecules are usually first bonded to the particle surface to attain electrostatic stabilization and then, further modified with a biomolecule or a specific ligand to provide special features. ${ }^{15,16}$

\footnotetext{
a)Email: rcosto@icmm.csic.es
}

Magnetic and chemical structures at the surface layer are usually greatly different from the nanoparticle core and strongly dependent on the synthesis process. As a result of the interactions between the particle surface and the coating, magnetic properties can be modified. Understanding these changes in magnetic behavior is critical for developing magnetic nanoparticles for biomedical applications ${ }^{17}$ since once the particles are internalized in the human body, they are inevitably encapsulated with biological ligands associated with the body's defense system. This process usually changes the nanoparticle aggregation state affecting the magnetic properties as well.

Leading researchers have previously described the effect of ligands chemically bonded to the nanoparticle surface on their magnetic properties. ${ }^{17-30}$ However, the variety in synthesis methods and grafting protocols hinder the comparison of the results, which are contradictory in some cases. Thus, some authors have described a decrease in saturation magnetization after coating due to high anisotropy field, spin-pinning phenomena or the presence of a dead layer at the surface. ${ }^{18-27}$ Other authors have found an improvement in the magnetic properties due to a reduction of the spin-canting or crystal field splitting energy evoked by the coordination of ligands at the particle surface. ${ }^{17,28-30}$

The aim of this work is to shed new light on the real effect of the coatings on the magnetic properties of iron oxide nanoparticles. Maghemite nanoparticles with high specific surface area $(3 \mathrm{~nm}$ in size) synthesized by a gas phase method in absence of surfactants and recrystallized in acid media are used as reference sample. This sample was coated with three biocompatible molecules (phosphonoacetic acid (PAA), pamidronic acid or carboxymethyl dextran) and systematically characterized and compared with bare nanoparticles. 


\section{MATERIALS AND METHODS}

\section{A. Synthesis of magnetic nanoparticles}

Iron oxide nanoparticles were synthesized by laser pyrolysis following a procedure described before. ${ }^{31,32}$ The experimental synthetic conditions were the following: $10^{\circ} \mathrm{C}$ precursor temperature, $60 \mathrm{~W}$ continuous wave $\mathrm{CO}_{2}$ laser power, $3.5 \mathrm{~mm}$ laser spot diameter, 400 mbar pressure, 1726 sccm Ar windows flux, $105 \mathrm{sccm}$ Ar axial flux, and a carrier gas flux formed by a mixture of $12 \mathrm{sccm}$ of $\mathrm{C}_{2} \mathrm{H}_{4}$ and 75 sccm of air. The particles were treated with nitric acid and iron nitrate to fully oxidize the magnetic iron oxide to maghemite, activate their surface and improve their magnetic and colloidal properties. ${ }^{33}$ Briefly, $350 \mathrm{mg}$ of the dried samples were treated with $2 \mathrm{ml}$ of $2 \mathrm{M}$ aqueous solution of $\mathrm{HNO}_{3}$ under sonication (ultrasonic bath ELMASONIC S30) for $15 \mathrm{~min}$. Then, $2 \mathrm{ml}$ of aqueous solution of $\mathrm{Fe}\left(\mathrm{NO}_{3}\right)_{3}$ $(1 \mathrm{M})$ and $6 \mathrm{ml}$ of water were added, followed by boiling to reflux for $30 \mathrm{~min}$. After cooling down at room temperature, $2 \mathrm{ml}$ of $2 \mathrm{M}$ aqueous solution of $\mathrm{HNO}_{3}$ were added and the sample was treated under sonication for $15 \mathrm{~min}$. Finally, the resulting samples were dialyzed in $5 \mathrm{~L}$ of distilled water by using a membrane with a 12000-14000 nominal molecular weight cut-off to remove the excess of acid and salts.

\section{B. Coating}

Acid-treated samples prepared by laser pyrolysis were coated as described below. Note that all the coating procedures are described for $2 \mathrm{ml}$ of an acid treated sample with no size selection $([\mathrm{Fe}]=6 \mathrm{mg} / \mathrm{ml})$.

The coatings aim to stabilize the particles in aqueous medium at physiological $\mathrm{pH}$ as well as to link the nanoparticles to a specific ligand. To this purpose, we have chosen negatively charged coatings which provide an active terminal group $\left(\mathrm{COOH}\right.$ or $\left.\mathrm{NH}_{2}\right)$ that can be further functionalized. In addition, the coating molecules have a backbone structure based on either a phosphonate or a carboxylate group. Phosphonoacetic acid $\left(\mathrm{PAA}=\left((\mathrm{HO})_{2} \mathrm{P}(\mathrm{O}) \mathrm{CH}_{2} \mathrm{CO}_{2} \mathrm{H}\right.\right.$ CAS:4408-78-0)) and Carboxymethyl dextran (CMdextran $\left.=\left(\mathrm{C}_{2} \mathrm{H}_{4} \mathrm{O}_{3 \mathrm{X}} \mathrm{NA}_{\mathrm{X}} C A S: 39422-83-8\right)\right)$ were purchased from Sigma Aldrich, whereas Pamidronic acid (3-amino-1hydroxypropane-1,1-diyl)bisphosphonic acid $\left(\mathrm{C}_{3} \mathrm{H}_{11} \mathrm{NO}_{7} \mathrm{P}_{2}\right.$ $C A S: 40391-99-9)$ was provided by Conier Chem\&Pharma. All the coatings are approved by the U.S. Food and Drug Administration (FDA) for intravenous administration.

\section{Phosphonate-based coating molecules}

PAA coating: $2 \mathrm{ml}$ of treated sample were dispersed in $120 \mathrm{ml}$ of distilled water at $\mathrm{pH} 2.5$. Then, $4 \mathrm{ml}$ of a solution $0.05 \mathrm{M}$ of PAA $(0.2 \mathrm{mmol})$ were added drop-wise under 30 min sonication. Pamidronic acid coating: As pamidronic acid is relatively difficult to dissolve in distilled water, previous to the coating, a stock solution of pamidronic acid was prepared by mixing $7.5 \mathrm{mg}$ of pamidronic acid $(0.032 \mathrm{mmol})$, $20 \mathrm{ml}$ of water and $65 \mu \mathrm{l}$ of $\mathrm{KOH} 1 \mathrm{M}$. The solution was stirred during $30 \mathrm{~min}$ at $40^{\circ} \mathrm{C}$ to facilitate the dissolution. $2 \mathrm{ml}$ of treated sample were dispersed in $20 \mathrm{ml}$ of distilled water at $\mathrm{pH}$ 2.5. Subsequently, the solution of pamidronic acid previously prepared was added drop by drop and sonicated for $30 \mathrm{~min}$. Differences in the coating molecule concentration are due to the different solubility of both compounds.

\section{Carboxylate-based coating molecules}

CM-dextran coating: First, $2 \mathrm{ml}$ of treated sample were dispersed in $1.25 \mathrm{ml}$ of distilled water at $\mathrm{pH} 2.5$ (adjusted with $\mathrm{HNO}_{3}$ ). Second, $3.125 \mathrm{ml}$ of a solution $2 \times 10^{-3} \mathrm{M}$ of CM-dextran $(6.25 \mu \mathrm{mol})$ were added drop by drop. Finally, the dispersion was sonicated for $12 \mathrm{~h}$.

In all the cases, the excess of coating was washed by dialysis against distilled water. The $\mathrm{pH}$ of the dispersions was adjusted first to 11 with $\mathrm{KOH} 1 \mathrm{M}$ and, then, to 7 with $\mathrm{HNO}_{3}$ $1 \mathrm{M}$. This forward/reverse $\mathrm{pH}$ adjustment guarantees a better anchoring of the coating molecule to the nanoparticle surface. $^{34}$

\section{RESULTS AND DISCUSSION}

Surface effects on magnetic properties are more noticeable in surfactant free nanoparticles with very small size since the surface: volume ratio is much larger. Moreover, in the sub- $5 \mathrm{~nm}$ particles synthesized by laser pyrolysis there are many surface anomalies (e.g., defects and spin canting) that made these nanoparticles especially sensitive to coatings processes and bonding. Thus, we have focused this study on $3 \mathrm{~nm}$ particles synthesized by laser pyrolysis.

Figure 1 shows a representative micrograph of the uncoated sample used as reference. The particles exhibited spheroidal shape and an average size of $3.0 \pm 0.8 \mathrm{~nm}$. The XRD patter is typical for maghemite ${ }^{35}$ and comparable to laser pyrolysis samples previously studied. ${ }^{33}$ The crystalline size, as calculated from Scherrer's equation using the half width of the (311) X-ray diffraction peak, is approximately $3 \mathrm{~nm}$, which is in good agreement with the TEM data. After the coating procedure the particle size is the same within experimental error.

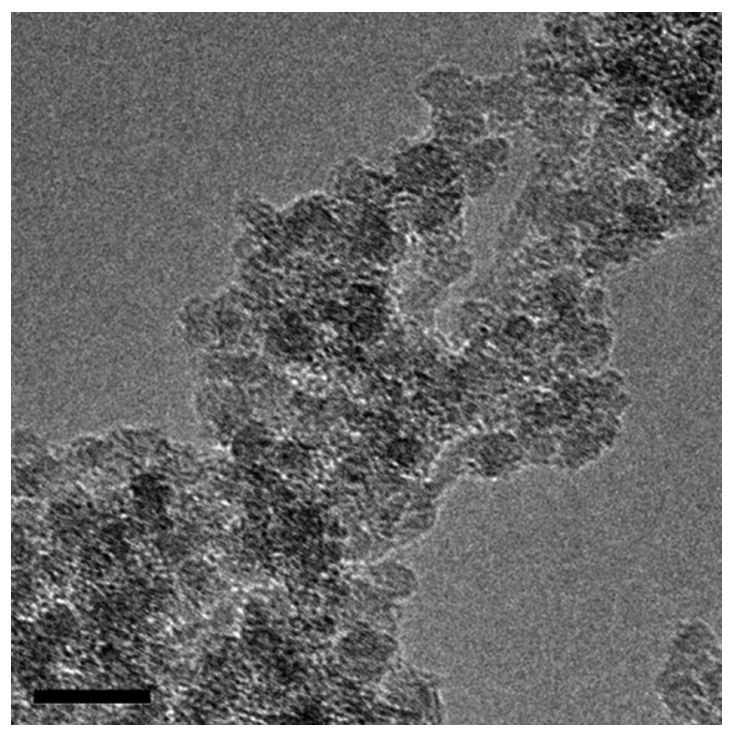

FIG. 1. TEM micrograph of the uncoated $3 \mathrm{~nm}$ iron oxide nanoparticles studied in this work. The scale bar is $10 \mathrm{~nm}$. 


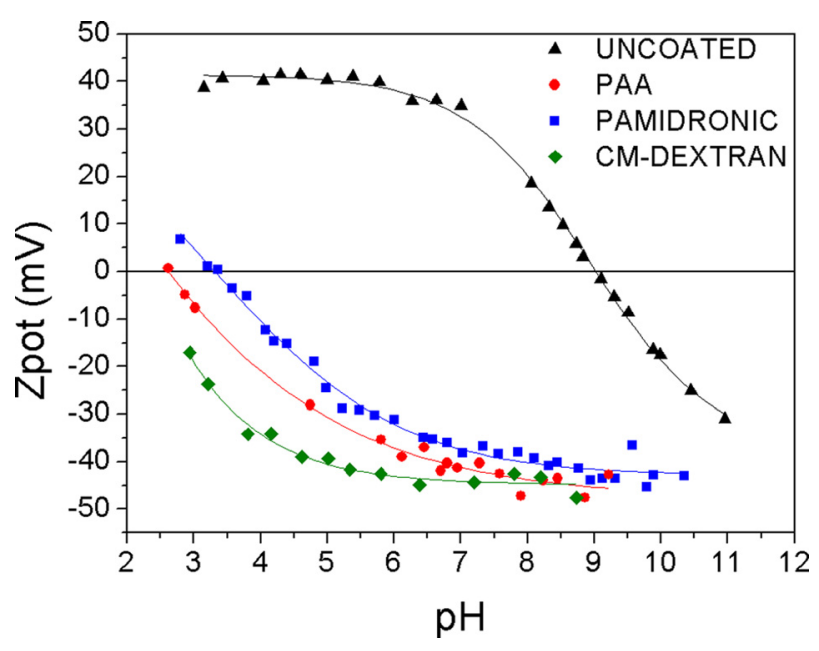

FIG. 2. Z-potential versus pH measured in $\mathrm{KNO}_{3} 10^{-2} \mathrm{M}$ for the uncoated acid-treated sample synthesized by laser pyrolysis (black) and the coated samples (blue, red, and green).

The success of the coating process is confirmed by the change in the isoelectric point value (Figure 2 and Table I), which is shifted towards lower $\mathrm{pH}$ values (from 9 to 3 or 2). After the coating process all the samples were negatively charged $(>30 \mathrm{mV})$ and stable at physiological $\mathrm{pH}(7.4)$.

The hydrodynamic diameter of coated particles is summarized in Table I. Aggregate size was increased almost three times $(17 \mathrm{~nm}$ in the uncoated sample at $\mathrm{pH}=3$ up to $76 \mathrm{~nm}$ in the sample coated with pamidronic acid). This increase in the hydrodinamic size cannot be only explained by the presence of the coating molecules around the magnetic particles but also reflects the usual fact that the coating leads to coated aggregates rather than coated individual nanoparticles. The smallest hydrodynamic sizes correspond to the PAA coating with a polydispersity degree of 0.26 in good agreement with the higher surface charge.

The chemical analysis of the samples based on the thermogravimetric data and the elemental analysis are presented in Table II.

The maximum coating efficiency is attained by the polymeric carboxydextran molecule. Notably, the amount of phosphate groups in the sample coated with the pamidronic acid (a biphosphonate) is nearly three times smaller than in the sample coated with phosphonoacetic acid. This could give us information about the type of bonding between the coating molecule and the particle surface. Thus, the pamidronic acid seems to be less densely packed on the surface as a consequence of its complex bonding in bidentate or double monodentate way could affect several coordinating positions

TABLE I. Colloidal characterization of the samples before and after the coating process. IEP under 3 were not measured due to the dissolution of the cell electrodes.

\begin{tabular}{lccccc}
\hline \hline Sample & $\begin{array}{c}\text { Z-ave } \\
(\mathrm{nm})\end{array}$ & PdI & $\begin{array}{c}\text { Size by Volume } \\
(\mathrm{nm})\end{array}$ & IEP & $\begin{array}{c}\text { Z-pot (mV) } \\
\mathrm{pH}=7\end{array}$ \\
\hline Uncoated & 17 & 0.172 & 9 & 9 & +35 \\
PAA & 56 & 0.265 & 15 & $<3$ & -41 \\
Pamidronic & 76 & 0.234 & 24 & 3 & -37 \\
CM-dextran & 68 & 0.207 & 33 & $<3$ & -44 \\
\hline \hline
\end{tabular}

TABLE II. Percentages of iron, oxygen, and phosphorous in the samples determined by chemical analysis. The weight loss percentage calculated from the thermogravimetrical analysis is also included.

\begin{tabular}{lcccc}
\hline \hline Sample & $\% \mathrm{TG}$ & $\% \mathrm{Fe}$ & $\% \mathrm{O}$ & $\% \mathrm{P}$ \\
\hline Uncoated & 20 & 56.2 & 24.1 & 0 \\
PAA & 18 & 49.5 & 21.2 & 1.7 \\
Pamidronic & 21.5 & 43.5 & 18.6 & 0.6 \\
CM-dextran & 72.6 & 14 & 6 & 0 \\
\hline \hline
\end{tabular}

on the surface while the PAA is bonded in a simple monodentate way reach higher surface densities (Figure 3).

This versatility of carboxylates and phosphonates for chemical coordination has been stressed in numerous studies as well as the influence of the carboxylate bridging mode on the resulting chemical and physical properties of the nanoparticles. $^{36-40}$ The presence of empty d orbitals in phosphorous has been mentioned as responsible for superexchange interactions among neighbor surface $\mathrm{Fe}$ atoms via monodentate bonds. ${ }^{27}$ For this reason, the understanding of the binding mode of the carboxylic and phosphonate groups to the particle surface would help us to foresee the properties of the coated nanoparticles. Consequently, we can take advantage of FTIR spectroscopy because it can differentiate symmetrical and asymmetrical coordination modes. Since the stretching mode frequencies are sensitive to the bond strength, IR spectroscopy can be directly used to investigate the binding behavior.

Figure 4 displays the FTIR spectra of the uncoated and coated nanoparticles. The bands in the low frequency region (under $750 \mathrm{~cm}^{-1}$ ) correspond to the $\mathrm{Fe}-\mathrm{O}$ bonds of the iron oxide nanoparticles. The broad vibration band between 3600 and $3200 \mathrm{~cm}^{-1}$ is associated with the $\mathrm{OH}$ stretching vibrations of water molecules (physisorbed molecular water) while those around $1620 \mathrm{~cm}^{-1}$ are associated with their bending mode. This last band at $1620 \mathrm{~cm}^{-1}$ could overlap with the $\mathrm{C}=\mathrm{O}$ stretch band of the unbounded carboxylic groups at $1600 \mathrm{~cm}^{-1}$ (in the PAA and CM-dextran coatings). A characteristic sharp band at $1381 \mathrm{~cm}^{-1}$ typically attributed to nitrates can be observed in the non-coated particles spectra. We should emphasize that the uncoated sample was stored at pH 3 (nitric acid); consequently, nitrate anions and nitric acid were present in this sample. The small bands at approximately $2930 \mathrm{~cm}^{-1}$ are attributable to the stretching mode of the $\mathrm{C}-\mathrm{H}$ from $\mathrm{CH}_{2}$.

CM-dextran-coated-particles spectrum exhibits polysaccharide characteristic bands at 1157 and $1014 \mathrm{~cm}^{-1}$, due to C-O vibrations, and at 917,852 , and $766 \mathrm{~cm}^{-1}$

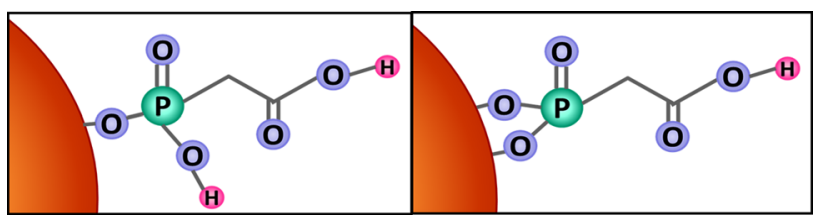

FIG. 3. Schematic representation of the monodentate (left) and bidentate (right) bonding options between the PAA and the iron oxide nanoparticle surface. As the pamidronic acid has two phosphonate groups, two more options are possible: The double monodentate and the double bidentate. 

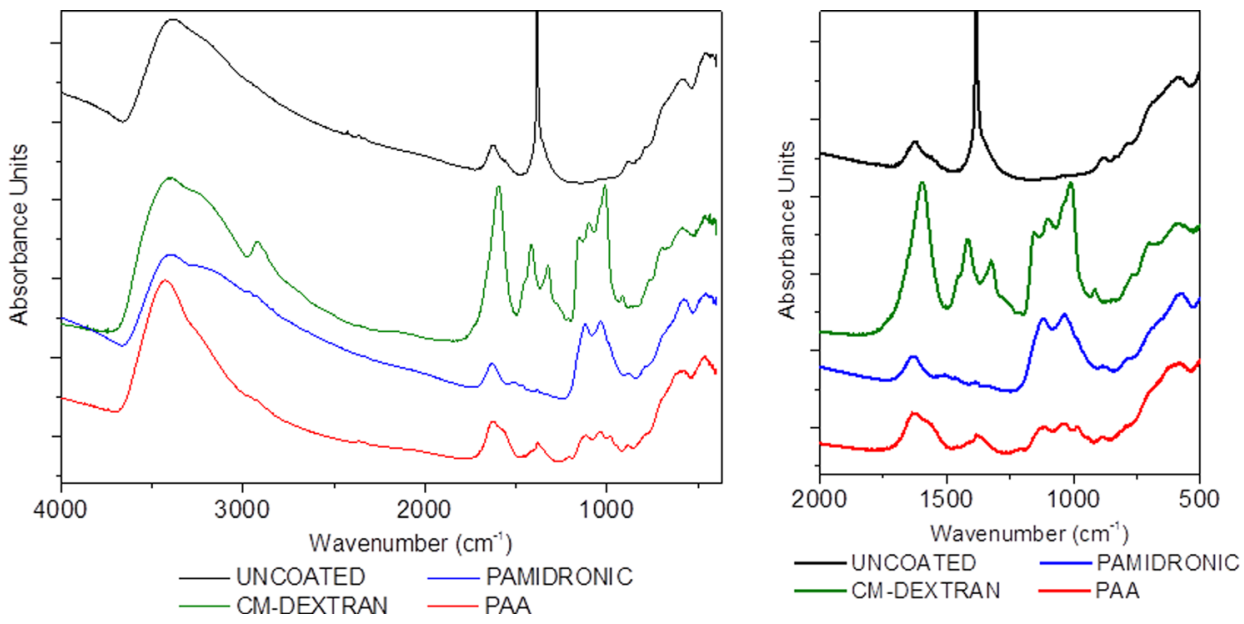

FIG. 4. FTIR spectra of the samples before and after the coating process. On the right side, the region between 200 and $500 \mathrm{~cm}^{-1}$ has been highlighted. corresponding to $\alpha$-glucopyranose ring deformation modes. Similar spectra were reported before for dextran-coated iron oxide nanoparticles ${ }^{2}$ and related to a soft binding (hydrogen bonding) between the dextran hydroxyl groups and the iron oxide particle surface. However, the ratio between the maximum intensity of the band at $1600 \mathrm{~cm}^{-1}$ and the band at $1420 \mathrm{~cm}^{-1}$ is smaller in the CM-dextran-coated particles than in the molecular CM-dextran ${ }^{35}$ indicating that part of the carboxylic groups of the CM-dextran are chemisorbed as a carboxylate onto the iron oxide nanoparticle surface, and the two oxygen atoms in the carboxylate are coordinated symmetrically to the Fe atoms.

Discriminating the different observed bands and assigning them to a given phosphonate complex is a difficult task. The different groups bounded to the $\mathrm{P}$ have a strong influence on the electronic density around the $\mathrm{P}$ and therefore on the position of the bands. Besides, the protonation states of the surface complexes influence the vibrational frequencies so the sample $\mathrm{pH}$ (even in the case of dried samples) may contribute to the band shift. Moreover, differences in methodology (as FTIR analysis of liquid or solid samples, vacuum, etc.) or even the hydration degree can lead to important differences in the FTIR spectra. Thus, large differences in band position and number are observed in the bibliography. ${ }^{41-48}$

The infrared spectra of both, particles coated with PAA and pamidronic acid, presented four bands at 1100, 1037, 983 , and $885 \mathrm{~cm}^{-1}$. This spectrum was related before to a monodentate bond between the particle surface and the phosphonate group. ${ }^{46}$ We could not ascertain the nature of the phosphonate iron bond that could be simple $\mathrm{FeOPO}(\mathrm{OH})(\mathrm{R})$ or bridged between two neighbor surface $\mathrm{Fe}$ atoms $\mathrm{Fe}_{2} \mathrm{O}_{2} \mathrm{PO}(\mathrm{R})$ as reported. ${ }^{27}$ The differences between both coatings can be attributed to the different organic radical, slightly different adsorption $\mathrm{pH}$, and the different phosphonates concentration.

Magnetic measurements of the coated and uncoated samples were performed and expressed in terms of iron mass (Figure 5).

In this work, the comparison between the different samples was done in terms of magnetization per gram of iron because otherwise the coating mass hided the effect on the magnetic properties. All the coating molecules used in this work show diamagnetic behavior and their contribution to the magnetic properties of the samples is negligible. However, the effect of the molecule mass is really noticeable in the case of the carboxymethyl dextran, whose molecular weight is almost 100 times larger than that of the rest of the coatings. Table III lists the saturation magnetization $\left(\mathrm{M}_{\mathrm{s}}\right)$, the magnetization at $50 \mathrm{kOe}\left(\mathrm{M}_{50 \mathrm{kOe}}\right)$ and the initial susceptibility $(\chi)$ of all the samples at room temperature and $5 \mathrm{~K}$ as a function of the sample mass and the iron mass. Besides, coercivity values are also included.

The magnetization data at $50 \mathrm{kOe}$ are included because the saturation magnetization $\left(\mathrm{M}_{\mathrm{s}}\right)$ cannot be accurately obtained by extrapolating $\mathrm{M}$ versus $1 / \mathrm{H}$ in the high field region $(1 / \mathrm{H} \neq 0$ in the high field region for these particles) due to the small particle size and disordered structure of the samples.
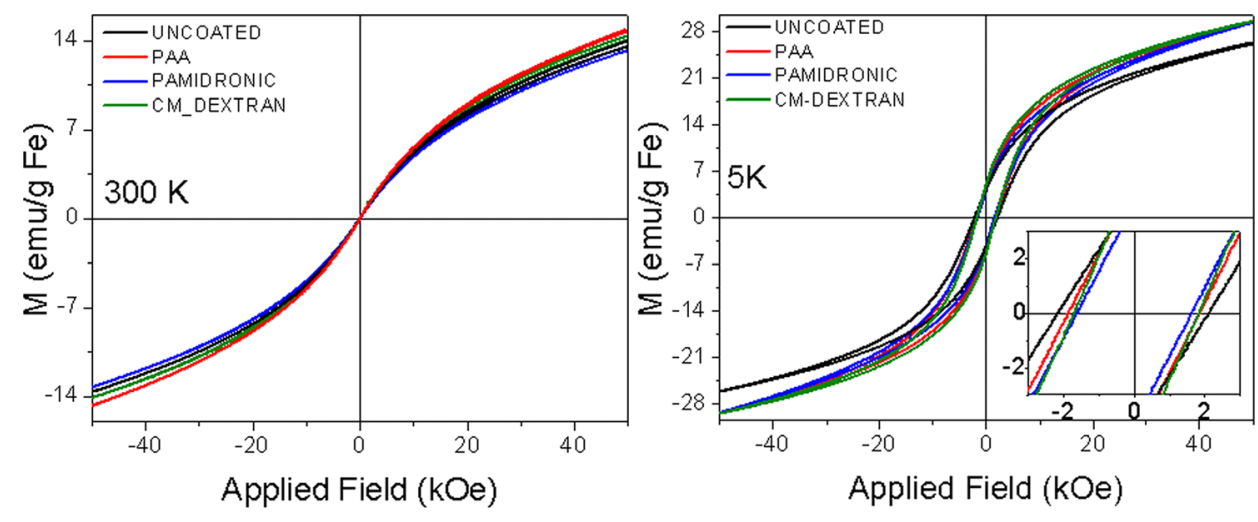

FIG. 5. Magnetization curves as a function of the iron mass at room temperature (left) and $5 \mathrm{~K}$ (right). The inset shows the low field magnetization at $5 \mathrm{~K}$ of the samples before and after the coating process. 
TABLE III. Saturation magnetization $\left(\mathrm{M}_{\mathrm{s}}\right)$, magnetization at $50 \mathrm{kOe}\left(\mathrm{M}_{50 \mathrm{kOe}}\right)$, and initial susceptibility $(\chi)$ of the coated and uncoated samples at room temperature and $5 \mathrm{~K}$ as a function of the sample mass and the iron mass. Besides, the coercivity (Hc) values are also included.

\begin{tabular}{|c|c|c|c|c|c|c|c|c|}
\hline \multirow[b]{2}{*}{ Sample } & \multirow[b]{2}{*}{$\mathrm{T}(\mathrm{K})$} & \multirow[b]{2}{*}{$\mathrm{Hc}(\mathrm{Oe})$} & \multicolumn{3}{|c|}{ g sample } & \multicolumn{3}{|c|}{$\mathrm{g} \mathrm{Fe}$} \\
\hline & & & $\begin{array}{l}\mathrm{M}_{50 \mathrm{kOe}} \\
(\mathrm{emu} / \mathrm{g})\end{array}$ & $\begin{array}{c}\mathrm{M}_{\mathrm{s}} \\
(\mathrm{emu} / \mathrm{g})\end{array}$ & $\begin{array}{c}\chi \\
(\mathrm{emu} / \mathrm{g} \cdot \mathrm{kOe})\end{array}$ & $\begin{array}{c}\mathrm{M}_{500 \mathrm{e}} \\
(\mathrm{emu} / \mathrm{g})\end{array}$ & $\begin{array}{c}\mathrm{M}_{\mathrm{s}} \\
(\mathrm{emu} / \mathrm{g})\end{array}$ & $\underset{(\mathrm{emu} / \mathrm{g} \cdot \mathrm{kOe})}{\chi}$ \\
\hline \multirow[t]{2}{*}{ Uncoated } & 5 & 2130 & 14.7 & 19.8 & 1.2 & 26.2 & 35.2 & 2.1 \\
\hline & RT & 0 & 7.7 & 11.6 & 0.4 & 13.7 & 20.6 & 0.7 \\
\hline \multirow[t]{2}{*}{ PAA } & 5 & 1850 & 14.5 & 19.0 & 1.3 & 29.4 & 38.5 & 2.6 \\
\hline & RT & 0 & 7.3 & 11.3 & 0.4 & 14.8 & 22.9 & 0.7 \\
\hline \multirow[t]{2}{*}{ Pamidronic } & 5 & 1610 & 12.8 & 18.0 & 1.5 & 29.4 & 41.5 & 3.4 \\
\hline & RT & 0 & 5.8 & 8.8 & 0.3 & 13.3 & 20.2 & 0.7 \\
\hline \multirow[t]{2}{*}{ CM-dextran } & 5 & 1750 & 4.1 & 5.4 & 0.4 & 29.5 & 38.7 & 2.9 \\
\hline & RT & 0 & 2.0 & 3.4 & 0.1 & 14.3 & 24.3 & 0.7 \\
\hline
\end{tabular}

All the samples show significant changes in magnetic properties after coating, especially at $5 \mathrm{~K}$. The $\mathrm{M}_{50 \mathrm{kOe}}$ at room temperature is approximately the same in all cases and around $10-14 \mathrm{emu} / \mathrm{g} \mathrm{Fe}$, while at $5 \mathrm{~K}$ higher magnetizations (approximately 25-28 emu/g Fe) are observed. Larger magnetization values are showed by coating the samples respect to the uncoated one, discarding a particle size reduction due to dissolution of the nanoparticles during the coating process at acidic pH. Similarly, the initial susceptibility is constant at room temperature but it is drastically increased at $5 \mathrm{~K}$. Moreover, the coercivity at $5 \mathrm{~K}$ is smaller after coating. These changes in the magnetic properties are more noticeable in the samples coated with pamidronic acid which shows a $12 \%$ increase in $\mathrm{M}_{50 \mathrm{kOe}}$, a $62 \%$ increase in $\chi$, and a $24 \%$ decrease in coercivity at $5 \mathrm{~K}$ respect to the uncoated sample.

Figure 6 shows magnetic moment versus temperature in zero field cooled (ZFC) and field cooled (FC) states. On the right hand side, the temperature of the maximum in the ZFC curve is depicted. Notably, in all cases TM is practically the same as in the uncoated sample (around $35 \mathrm{~K}$ ) showing no changes in the particle size distribution. ZFC and FC curves for all the samples tend to be superimposed just after TM following the Langevin law in spite of the presence of aggregates as observed by Dynamic Light Scattering (DLS) measurements and therefore weak interactions. ${ }^{49}$

As the coating molecules are bonded to the particle surface, they could affect somehow surface disorder which can lead to loop displacement after field cooling. ${ }^{33}$ Thus, field cooling hysteresis loops at $50 \mathrm{kOe}$ were measured (Figure 7) and the magnitude of this shift $\left(\mathrm{H}_{\mathrm{S}}\right)$ and the coercivity $(\mathrm{Hc})$ were calculated. The magnitude of the loop shift $\left(\mathrm{H}_{\mathrm{S}}\right)$ and coercivity $(\mathrm{Hc})$ were calculated by $\mathrm{H}_{\mathrm{S}}=-\left(\mathrm{H}_{0}{ }^{+}+\mathrm{H}_{0}{ }^{-}\right) / 2$ and $\mathrm{Hc}=\left(\mathrm{H}_{0}{ }^{+}-\mathrm{H}_{0}{ }^{-}\right) / 2$, respectively. The results of these calculations are listed on Table IV.

The coercivity $(\mathrm{Hc})$ is reduced in all cases and $\mathrm{H}_{\mathrm{S}}$ decreases in the samples coated with CM-dextran and pamidronic acid, but not in the sample coated with PAA. Again, the sample coated with pamidronic acid shows the most drastic effect, with a reduction of $10 \%$ in $\mathrm{H}_{\mathrm{S}}$.

It is known that the effect of the coatings on the magnetic properties could be attributed to (a) change in the particlesize distribution (b) particle interactions or (c) spin canting.
The nature of this study enables us to discard changes in particle size distribution since coating do not modify size distribution. On the other hand, interparticle interactions may affect the magnetic behaviour of the samples. ${ }^{50}$ However, magnetic properties of CM-dextran-coated sample ( $72 \%$ organic content, Table II) where the interparticle interactions should be smaller, follows the same trend as the others and presents larger $\mathrm{M}_{50 \mathrm{kOe}}$ and smaller coercivity than PAA-coated sample (18\% organic content), where smaller interparticle distances and larger interactions are expected.

In addition, the effect of aggregation and interparticle interactions becomes less significant if we compare PAA and Pamidronic acid coated particles. The size of the coating molecule and amount of coating is comparable (18\% and

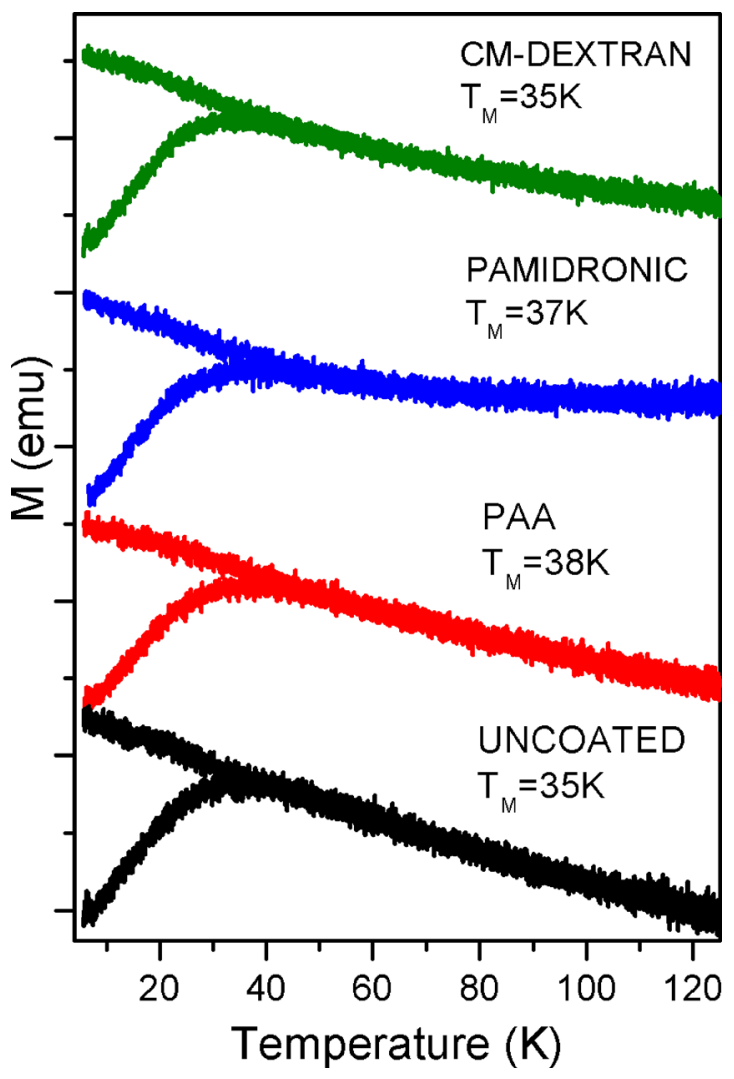

FIG. 6. ZFC-FC curves of the coated and uncoated samples. On the right hand side, the TM of every sample is noted. 


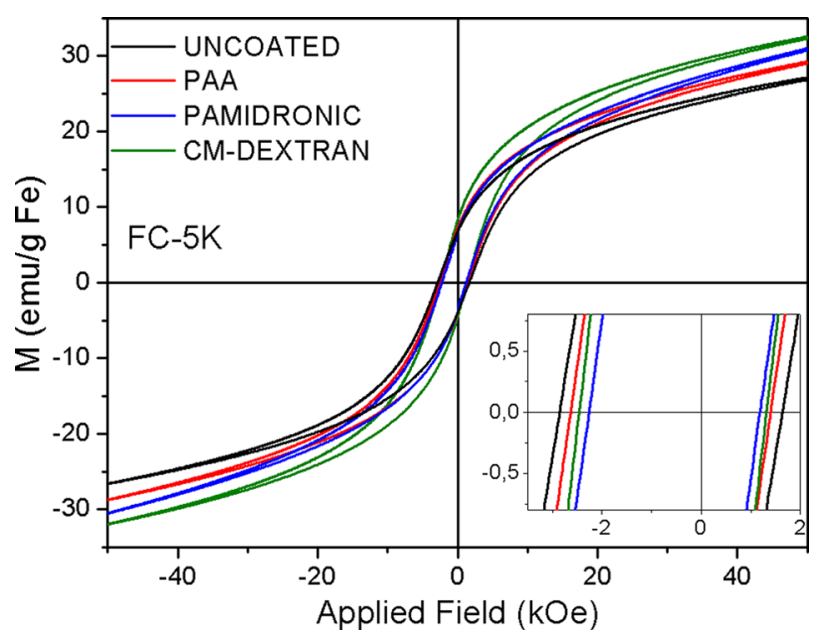

FIG. 7. Hysteresis loops at $5 \mathrm{~K}$ of the coated and uncoated samples after field cooling (50 KOe). The inset shows the low field region.

$21 \%$, respectively), however, the aggregate size is significantly larger for the particles coated with pamidronic acid (15 and $24 \mathrm{~nm}$ for particles coated with PAA and pamidronic acid, respectively). Assuming a loose random packing (packing density $\approx 0.6$ ), the aggregates of the sample coated with pamidronic acid would have at least three times more particles than the PAA aggregates (310 and 75 particles per aggregate, respectively) but it shows smaller exchange anisotropy field.

To sum up, we consider that in our case changes in the magnetic properties with the coating are consequence of the reduction of the surface disorder and spin canting. As a result, the atoms of the coating molecule would take the positions of the missing oxygen atoms at the nanoparticle surface enlarging the crystal network and thus, decreasing the surface disorder.

The sample coated with CM-dextran shows an enhancement on the magnetic properties. This conclusion is similar to the attained in for the oleic acid coating procedures on microemulsions at low temperatures ${ }^{51}$ or by the coating with para-substituted benzoic acid derivatives ${ }^{17}$ but opposite to the obtained for the standard oleic acid coating during the synthesis at high temperatures onto iron oxide nanoparticles of similar sizes. ${ }^{52}$ It was also reported a reduction of the saturation magnetization after the coordination of citric acid onto cobalt ferrite nanoparticles of the same size than the studied in this work. ${ }^{23}$ It appears that the macroscopic effect of carboxylates on the magnetic properties of iron oxide nanoparticles depends on the nature of the dominant surface

TABLE IV. Loop shift $\left(\mathrm{H}_{\mathrm{S}}\right)$ and coercivity $(\mathrm{Hc})$ values of the uncoated and coated samples.

\begin{tabular}{lcc}
\hline \hline & \multicolumn{2}{c}{ FC } \\
\cline { 2 - 3 } Sample & $\mathrm{H}_{\mathrm{S}}(\mathrm{Oe})$ & $\mathrm{Hc}(\mathrm{Oe})$ \\
\hline Uncoated & 630 & 2230 \\
PAA & 630 & 2020 \\
Pamidronic & 555 & 1725 \\
CM-dextran & 580 & 1890 \\
\hline \hline
\end{tabular}

bond (bidentate or monodentate), the packing density of coating molecules at the surface and the surface disorder of the original sample that depends on the synthesis route. In addition at subnanometer level it has been proved that the oleic acid coordination to a nearly perfect iron oxide surfaces has a positive influence on the magnetism. ${ }^{53}$

Similar conclusion was attained with the phosphonates. Notably, the amount of phosphate groups in the sample coated with the pamidronic acid is one third approximately of that in the sample coated with phosphonoacetic acid. However, the improvement in the magnetic properties at $5 \mathrm{~K}$ is significantly larger in the samples coated with pamidronic acid. This suggests that most probably, the pamidronic acid is attached to the particle surface by a double-monodentate bond $(\mathrm{FeO})_{2} \mathrm{PO}(\mathrm{R})$ similar than the reported by Yee et al. ${ }^{27}$ This type of anchoring would facilitate the coordination of ligands within the frame of the crystal field splitting energy and thus, induce a stronger reduction of the surface disorder. The smaller effect of the phosphonoacetic acid could be related with the more electronegative character of the free carboxylate group in this molecule, as proposed by Vestal et al. ${ }^{17}$

We could therefore conclude that in the case of ultrasmall maghemite nanoparticles, both carboxylates and phosphonates reduce the spin canting on the surface. The effect of the phosphonates is larger due to a double-monodentate or bidentate bond that leads to higher surface order than the carboxylate anchored to the surface by a single bond.

The observed loop shift has been interpreted as an exchange bias between a ferromagnetic or antiferromagnetic core and the uncompensated spins of the spin-glass surface. ${ }^{54,55}$ In this case, the lack of saturation could be responsible for the loop shift and the reduction of the magnitude of this loop shift is directly caused by a decrease in the surface disorder.

\section{CONCLUSIONS}

Stable colloidal dispersions of magnetic iron oxide nanoparticles at physiological $\mathrm{pH}$ were prepared by coating $3 \mathrm{~nm}$ maghemite particles synthesized by laser pyrolysis with PAA, pamidronic acid and carboxymethyl dextran.

The effect of these coatings on the magnetic properties was studied with magnetization curves, ZFC-FC and studies of the exchange anisotropy field. We conclude that in this study the differences in magnetic behavior are due to the reduction of the surface disorder, and, to a lesser degree, to interparticle interactions. Notwithstanding its limitations, this study does suggest that the number of bonds between a molecule and the particle surface has a strong effect on the reduction of the surface disorder. The higher reduction of the exchange anisotropy field is achieved by the molecules attached to the particle surface by double-monodentate or bidentate bonds.

\section{ACKNOWLEDGMENTS}

This work was partially supported by grants from the Spanish Ministry of Economy and Competitiveness (MAT2011-23641), the Madrid regional government (S009/ 
MAT-1726 to MPM) and the $7^{\text {th }}$ framework programme of the European Community (Nanomag 604448). Dr. C. Robic and Dr. M. Port from Gerbet are thanked for fruitful discussion. Dr. R. Costo also acknowledges Gerbet staff for their support and warm welcome during her stay at the company.

${ }^{1}$ S. Laurent, D. Forge, M. Port, A. Roch, C. Robic, E. Vander, and R. N. Muller, Chem. Rev. 108, 2064 (2008).

${ }^{2}$ M. C. Bautista, O. Bomati-Miguel, X. Zhao, M. P. Morales, T. GonzalezCarreño, R. Perez de Alejo, J. Ruiz-Cabello, and S. VeintemillasVerdaguer, Nanotechnology 15, S154-S159 (2004).

${ }^{3}$ E. Duguet, S. Vasseur, S. Mornet, G. Goglio, A. Demourgues, J. Portier, F. Grasset, P. Veverka, and E. Pollert, Bull. Mater. Sci. 29, 581 (2006).

${ }^{4}$ A. F. Thünemann, D. Schütt, L. Kaufner, U. Pison, and H. Möhwald, Langmuir 22, 2351 (2006).

${ }^{5}$ N. Kohler, C. Sun, A. Fichtenholtz, J. Gunn, C. Fang, and M. Zhang, Small 2, 785 (2006).

${ }^{6}$ C. Duanmu, I. Saha, Y. Zheng, B. M. Goodson, and Y. Gao, Chem. Mater. 18, 5973 (2006).

${ }^{7}$ B. Srinivasan and X. Huang, Chirality 20, 265 (2008).

${ }^{8}$ A. P. Philipse, M. P. B. Van Bruggen, and C. Pathmamanoharan, Langmuir 10, 92 (1994).

${ }^{9}$ P. Tartaj and C. J. Serna, J. Am. Chem. Soc. 125, 15754 (2003).

${ }^{10}$ M. Chen, S. Yamamuro, D. Farrell, and S. A. Majetich, J. Appl. Phys. 93, 7551 (2003).

${ }^{11}$ C. K. Lo, D. Xiao, and M. M. F. Choi, J. Mater. Chem. 17, 2418 (2007).

${ }^{12}$ Y. J. Kim, J. H. Yu, and J. H. Ahn, J. Alloys Compd. 434-435, 675-677 (2007).

${ }^{13}$ S. Veintemillas-Verdaguer, Y. Leconte, R. Costo, O. Bomati-Miguel, B. Bouchet-Fabre, M. P. Morales, P. Bonville, S. Perez-Rial, I. Rodriguez, and N. Herlin-Boime, J. Magn. Mag. Mater. 311, 120 (2007).

${ }^{14}$ M. Sevilla, P. Valle-Vigon, P. Tartaj, and A. B. Fuertes, Carbon 47, 2519 (2009).

${ }^{15}$ C. C. You, A. Verma, and V. M. Rotello, Soft Matter 2, 190 (2006).

${ }^{16}$ J. R. McCarthy and R. Weissleder, Adv. Drug Delivery Rev. 60, 1241 (2008).

${ }^{17}$ C. E. Vestal and Z. J. Zhang, J. Am. Chem. Soc. 125, 9828 (2003).

${ }^{18}$ A. E. Berkowitz, J. A. Lahut, I. S. Jacobs, L. M. Levinson, and D. W. Forester, Phys. Rev. Lett. 34, 594 (1975).

${ }^{19}$ K. J. Davies, S. Wells, and S. W. Charles, J. Magn. Mag. Mater. 122, 24 (1993).

${ }^{20}$ Y. Koseoglu, J. Magn. Magn. Mater. 300, e327-e330 (2006).

${ }^{21}$ N. Jain, Y. Wang, S. K. Jones, B. S. Hawkett, and G. G. Warr, Langmuir 26, 4465 (2009).

${ }^{22}$ A. Karimi, B. Denizot, F. Hindre, R. Filmon, J. M. Greneche, S. Laurent, T. J. Daou, S. Begin-Colin, and J. J. Le Jeune, J. Nanopart. Res. 12, 1239 (2010).

${ }^{23}$ A. T. Ngo, P. Bonville, and M. P. Pileni, Eur. Phys. J. B 9, 583 (1999).

${ }^{24}$ G. Kataby, M. Cojocaru, R. Prozorov, and A. Gedanken, Langmuir 15, 1703 (1999).

${ }^{25}$ G. Kataby, Y. Koltypin, A. Ulman, I. Felner, and A. Gedanken, Appl. Surf. Sci. 201, 191 (2002).

${ }^{26}$ K. V. P. M. Shafi, A. Ulman, X. Yan, N. L. Yang, C. Estournes, H. White, and M. Rafailovich, Langmuir 17, 5093 (2001).
${ }^{27}$ C. Yee, G. Kataby, A. Ulman, T. Prozorov, H. White, A. King, M. Rafailovich, J. Sokolov, and A. Gedanken, Langmuir 15, 7111 (1999).

${ }^{28}$ T. J. Daou, J. M. Greneche, G. Pourroy, S. Buathong, A. Derory, C. Ulhaq-Bouillet, B. Donnio, D. Guillon, and S. Begin-Colin, Chem. Mater. 20, 5869 (2008).

${ }^{29}$ E. Tronc and J. P. Jolivet, Hyperfine Interact. 28, 525 (1986).

${ }^{30}$ D. Prodan, C. Chaneac, E. Tronc, J. P. Jolivet, R. Cherkaour, A. Ezzir, M. Nogues, and J. L. Dormann, J. Magn. Magn. Mater. 203, 63 (1999).

${ }^{31}$ S. Veintemillas-Verdaguer, M. P. Morales, and C. J. Serna, Mater. Lett. 35, 227 (1998).

${ }^{32}$ S. Veintemillas-Verdaguer, M. P. Morales, and C. J. Serna, Appl. Organomet. Chem. 15, 365 (2001).

${ }^{33}$ R. Costo, V. Bello, C. Robic, M. Port, J. F. Marco, M. P. Morales, and S. Veintemillas-Verdaguer, Langmuir 28, 178 (2012).

${ }^{34}$ A. G. Roca, S. Veintemillas-Verdaguer, M. Port, C. Robic, C. J. Serna, and M. P. Morales, J. Phys. Chem. B. 113, 7033 (2009).

${ }^{35}$ See supplementary material at http://dx.doi.org/10.1063/1.4908132 for XRD diffractogram and FTIR spectra of the molecular CM-dextran.

${ }^{36}$ S. Durot, C. Policar, G. Pelosi, F. Bisceglie, T. Mallah, and J. P. Mahy, J. Inorg. Chem. 42, 8072 (2003).

${ }^{37}$ D. Fiorani, Surface Effects in Magnetic Nanoparticles (Springer, New York, 2005).

${ }^{38}$ H. Duan, M. Kuang, X. Wang, Y. A. Wang, H. Mao, and S. Nie, J. Phys. Chem. C. 112, 8127 (2008).

${ }^{39}$ D. Ortega, E. Velez-Fort, D. A. Garcia, R. Garcia, R. Litran, C. BarreraSolano, M. Ramirez-del-Solar, and M. Dominguez, Philos. Trans. R. Soc. A 368, 4407 (2010).

${ }^{40}$ B. Issa, I. M. Obaidat, B. A. Albiss, and Y. Haik, Int. J. Mol. Sci. 14, 21266 (2013).

${ }^{41}$ Y. Lalatonne, C. Paris, J. M. Serfaty, P. Weinmann, M. Lecouvey, and L. Motte, Chem. Commun. 2008, 2553.

${ }^{42}$ M. Stachen, M. P. Morales, M. Ocaña, and C. J. Serna, Phys. Chem. Chem. Phys. 1, 4465 (1999).

${ }^{43}$ K. D. Kwon and J. D. Kubicki, Langmuir 20, 9249 (2004).

${ }^{44}$ E. J. Elzinga and D. L. Sparks, J. Colloid Interface Sci. 308, 53 (2007).

${ }^{45}$ B. C. Barja, J. Herszage, and M. Dos Santos Alfonso, Polyhedron 20, 1821 (2001).

${ }^{46}$ P. Persson, N. Nilsson, and S. Sjoberg, J. Colloid Interface Sci. 177, 263 (1996).

${ }^{47}$ M. I. Tejedor-Tejedor and M. A. Anderson, Langmuir 6, 602 (1990).

${ }^{48}$ T. J. Daou, S. Begin-Colin, J. M. Greneche, F. Thomas, A. Derory, P. Bernhardt, P. Legare, and G. Pourroy, Chem. Mater. 19, 4494 (2007).

${ }^{49}$ P. Allia, M. Coisson, P. Tiberto, F. Vinai, M. Knobel, M. A. Novak, and W. C. Nunes, Phys. Rev. B 64, 144420 (2001).

${ }^{50}$ D. Farrell, Y. Cheng, R. W. McCallum, M. Sachan, and S. A. Majetich, J. Phys. Chem. B 109, 13409 (2005).

${ }^{51}$ M. Singh, P. Ulbrich, V. Prokopec, P. Svoboda, E. Šantavá, and F. Štěpánek, J. Magn. Magn. Mater. 339, 106 (2013).

${ }^{52}$ Y. Yuan, D. Rende, C. L. Altan, S. Bucak, R. Ozisik, and D. A. BorcaTasciuc, Langmuir 28, 13051 (2012).

${ }^{53}$ J. Salafranca, J. Gazquez, N. Pérez, A. Labarta, T. S. Pantelides, J. S. Pennycook, X. Batlle, and M. Varela, Nano Lett. 12, 2499 (2012).

${ }^{54}$ N. J. O. Silva, V. S. Amaral, A. Urtizberea, R. Bustamante, A. Millan, F. Palacio, E. Kampert, U. Zeitler, S. De Brion, A. A. Iglesias, and A. Labarta, Phys. Rev. B 84, 104427 (2001).

${ }^{55}$ V. Skumryev, S. Stoyanov, Y. Zhang, G. Hadjipanayis, D. Givord, and J. Nogués, Nature 423, 850 (2003). 